Steps 11 and 12 ( $A$ and $A+$ equivalent) Employer, senior award holder and either the consultant's Royal College or Specialty Association.

On receipt of the $\mathrm{CV}$ form the Secretariat will seek citations from the employer and senior award holder for step 10, and from the employer, senior award holder, and nominated Royal College or Specialty Association for steps 11 and 12 . The Secretariat will provide the citation with a copy of the completed CV form.

\section{Honorary Fellowships}

Nominations for the College's Honorary Fellowship will be discussed at the October meeting of the Court of Electors.

The regulations of the College state under Bye-Law Section $V$ that 'Subject to the Regulations the College may elect as an Honorary Fellow any person, whether or not that person is a member of the medical profession, who either is eminent in psychiatry or in allied or connected sciences or disciplines or has rendered distinguished service to humanity in relation to the study, prevention or treatment of mental illness or to subjects allied thereto or connected therewith or has rendered notable service to the College or to the Association'

Nomination forms are available from Miss K. Hillman, Department of Postgraduate Educational Services (e-mail: khillman@rcpsych.ac.uk), to whom nominations for the Honorary Fellowship should be sent by 30 June 2006. Such nominations must contain recommendations by no fewer than six Members of the College, and include full supporting documentation.

\section{Special Committee on Professional Governance and Ethics - Sub-Committees on Ethics and Confidentiality}

The new Special Committee on Professional Governance and Ethics (SCPGE) will be established at the AGM on 11 July 2006. Membership will comprise recently appointed members of the Special Committee on Clinical Governance, the Chair of the new Ethics Sub-Committee and the Chair of the new Confidentiality Sub-Committee.
SCPGE will advise on and coordinate the College's activities and responses to a wide range of issues relating to professional standards (including professional ethics and confidentiality), professional accountability, appraisal and reflective practice, inter-professional relationships and core standards relating to clinica performance common to all psychiatrists

The new Committee will:

- liaise with Faculties and educational committees (the new Education, Training and Standards Committee and the Continuing Professional Development Committee) with regard to matters of professional governance

- provide a conduit for, and advise on aspects of 'Standards for Better Health' (England) and similar programmes in the other countries relevant to the clinical practice and standards of psychiatry and psychiatrists;

- promulgate best practice in the field of clinical governance given the current understanding and usage of the term;

- relate with regulatory bodies, including the General Medical Council, with regard to issues of good medical practice and performance;

- oversee the ongoing preparation, editing and consultation on core Good Psychiatric guidance (CR125), and other guidance documents published in the Good Psychiatric Practice series, including Confidentiality and Information Sharing (CR133) (prepared by the ConfidentialityAdvisory Group) and the revision of CR101 (Vulnerable Patients; Vulnerable Doctors: Good Practice in our Clinical Relationships);

- develop College initiatives for psychiatrists employed within and outside the NHS, specifically in the developing field of appraisal and revalidation.

The following new sub-committees will be established to focus on ethical and confidentiality issues. The chairs of these sub-committees will be members of the SCPGE. The terms of reference for these two sub-committees will be agreed by SCPGE. The sub-committees will report directly through the SCPGE on matters relating specifically to areas of complex ethics and ethical dilemmas for psychiatry, and responding to, issuing guidance on, and advising the membership about patient/clinical confidentiality.

\section{Ethics Sub-Committee}

The remit of this committee will include:

- working with the SCPGE on the development and review of the College's core Good Psychiatric Practice guidance (CR125):

- advising the SCPGE and the Central Executive Committee on ethical issues

- offering support in making ethical decisions;

- considering relevant consultation documents;

- promoting the importance of ethical training during all stages of a psychiatrist's career.

It is anticipated that the Committee will meet at the College four to five times a year, with business also carried out by email.

\section{Confidentiality \\ Sub-Committee}

The remit of this committee will include:

- development and review of the College's good practice guidance on Confidentiality and Information Sharing (CR133);

- advising the SCPGE and the Central Executive Committee on medical confidentiality and patient privacy and medical confidentiality:

- providing advice to members;

- considering relevant consultation documents.

It is anticipated that the Committee will meet at the College three to four times a year, with business also carried out by email, including consultation with individual members according to their expertise.

Members with interest and expertise in ethics or confidentiality who wish to apply for membership or chairmanship of the Ethics or Confidentiality Sub-Committees are invited to write to Vanessa Cameron, Chief Executive by Monday 22 May 2006, enclosing a copy of their CV. Interviews will be held at the College on Thursday 1 June 2006

Members will be asked to confirm that they have discussed their application and the time commitment involved with their employing authority and that this would be supported should their application be successful. 